TRANSGRESIÓN Y AUTORREFERENCIA. UN ACERCAMIENTO

ETNOGRÁFICO AL DISFRUTE DE NARCOCORRIDOS DESDE UNA CIUDAD DEL NORTE DE MÉXICO

\title{
Transgression and Self-Reference. An Ethnographic Approach to Enjoying Narcocorrides from a City of North of México
}

\author{
FERDinANDO ALFONSO ARMENTA IRURETAGOYENA \\ UNIVERSIDAD AUTÓNOMA DE BAJA CALIFORNIA \\ ferdinando_alfonso@hotmail.com
}

\begin{abstract}
Resumen: el siguiente artículo aborda la manera en que las personas se apropian de las representaciones del narcotráfico desde la música. El ciclo de producción de la música comercial se sintetiza en el consumo, ya que es en el disfrute de los escuchas que se cumple gran parte de su cometido. Sin embargo, quienes asisten a eventos musicales donde se tocan narcocorridos, no necesariamente concuerdan con el mundo de vida de los narcotraficantes. A través de un registro etnográfico de espacios donde se tocan narcocorridos en Mexicali, México, atenderé a la pregunta sobre qué hace disfrutable a la narcomúsica.
\end{abstract}

Palabras clave: transgresión, narcocorrido, disfrute de la música, autorreferencia

\begin{abstract}
The following article addresses the way people appropriate the symbolic forms of drug trafficking through music. For popular music, consumption epitomizes the process of musical production, specifically with the listener's enjoyment. However, attending musical events where narcocorridos are habitually played does not mean partaking in the world of narcos. Through ethnographic record of places where narcocorridos are performed in Mexicali city, Mexico, I'll explore what makes narco-music appealing for the assistants.
\end{abstract}

Keywords: Transgression, Narcocorrido, Enjoyment of Music, SelfReference 
Las representaciones del tráfico de drogas, comúnmente denominadas "narcocultura", son parte de un fenómeno derivativo pero no necesariamente constitutivo del narcotráfico. La narcocultura, además de constituir la actividad humana destinada al tráfico de sustancias ilícitas, puede conformar otras prácticas tales como las que se inscriben en la producción de formas simbólicas desde diversos campos como la música, el cine o la literatura. Quienes reproducen, crean o consumen uno u otro producto cultural referente al narco no necesariamente simpatizan con su mundo de vida. El actual ascenso y diversificación de dichos productos en la cotidianidad nos hace voltear a la cuestión sobre cómo nos apropiamos de la narcocultura. En el entendido de que el público no transita pasivamente con su "falsa conciencia" y que la ideología es más bien un sustrato sobre el cual se piensa, hace y elije conscientemente (Hall, 2010: 238), me interesa esta apropiación desde la música, en específico desde los escuchas de narcocorridos en México.

Con la finalidad de explorar este fenómeno desde el consumo musical, me enfocaré en dos elementos base en los narcocorridos: las representaciones que recrean en el escucha la sensación de transgredir tras el consumo de un narcocorrido y la capacidad de estas expresiones para generar "autorreferencia", entendiendo esta última como la cualidad para hacer sentir al escucha como sujeto de la narración. Dado que el análisis se centra en el disfrute de la música, es necesario contemplar múltiples dimensiones de estudio: lo sonoro, el contenido de los narcocorridos y la socialización de la música. Sobre la secuencia que seguirá este trabajo, primero se introduce una reflexión teórica sobre la relación entre música e imaginario del tráfico de drogas como un fenómeno que se confabula en el horizonte de la contemporaneidad; asimismo se presenta una breve revisión de antecedentes de estudio en torno a las representaciones de la transgresión y su relación con el presente análisis. Después, se desarrolla la idea de "autorreferencia" como un fenómeno de autoafirmación en el cual el recurso narrativo de la primera persona juega un papel importante en la asimilación del escucha. Posteriormente, se esboza el contexto fronterizo de la ciudad de Mexicali con Estados Unidos, junto con algunas precisiones teórico-metodológicas al analizar el disfrute de la música. Una vez acotados los conceptos, el contexto y la metodología de estudio, se presenta el correlato empírico del trabajo mediante un registro etnográfico de los lugares donde los narcocorridos son tocados en vivo y, finalmente, se cierra con una reflexión sobre el sentido social de los narcocorridos hoy en día.

\section{Narcomúsicas: los marcos sonoros de la transgresión}

El término "narcocultura" resulta controvertido debido a las imprecisiones que entraña. En México, su preponderante uso mediático refiere a las expresiones sobre el tráfico de drogas. Algunos estudiosos del tema han empleado este término como categoría de análisis (véanse, por ejemplo, Valenzuela, 2015, 2012; Maihold y Sauter, 2012). Retomo a Maihold y Sauter (2012), quienes instan a dimensionar el prefijo "narco-" desde diversas aristas; proponen distinguir las expresiones que provienen desde dentro y las que se producen desde fuera del narcotráfico. En este sentido, por "narcocultura" me referiré al 
conjunto de imágenes que "se encuentran en el intersticio entre lo narco y el narco, ya que provienen del ámbito del crimen organizado, pero también pertenecen al imaginario colectivo" (Maihold y Sauter, 2012: 67). ${ }^{1}$ En lo sucesivo, hablaré menos de "narcocultura" y, en cambio, me referiré a ello como un conjunto de prácticas, narrativas y discursos relacionados con las expresiones del tráfico de drogas.

Música y expresiones del narcotráfico configuran dos órdenes discursivos que se han fundido en la historia contemporánea de América Latina y otros lugares del mundo. Stuart Hall, personaje insigne en los Cultural Studies, empleó el concepto de "articulación" para dar cuenta del estado de la cultura tras la posguerra, periodo a partir del cual se concedería un papel decisivo a los medios de comunicación masiva en la producción y consumo de bienes culturales. Por "articulación”, Hall se refirió al engarce entre diversos elementos discursivos que crean unidad para hacer inteligible una situación histórica (Hall, 2010: 49). La articulación entre música e imágenes asociadas al tráfico de drogas deviene así en "subgéneros musicales" que, a la postre, circulan como productos culturales ampliamente aceptados por públicos trasnacionales.

Diversos estilos musicales alrededor del mundo reservan un rubro al imaginario del narcotráfico: el gangsta rap derivado del hip hop dentro y fuera de Estados Unidos (Wald, 2001); los "corridos prohibidos" como parte de la "música de popular" en Colombia (Rincón, 2009); la neomelodici criminal a partir de la música neomelódica en Italia (Ravveduto, 2012); también el proibidão funk en el funk carioca de Brasil (Sneed, 2007) o la cumbia villera en Argentina (Cragnolini, 2006). Se trata de manifestaciones musicales que forman parte de marcos sonoros más amplios, que se producen desde particularidades geográficas, políticas y culturales, y que se conforman tanto de elementos locales como de otros apropiados del exterior. Pese a las enormes diferencias musicales entre sí, estas expresiones proyectan formas de vida en contextos permeados por el tráfico de drogas, violencia y exclusión. En ese sentido, ocupan un lugar social similar al que ocupa el "narcocorrido" actualmente en la música norteña en México. En palabras de Omar Rincón (2013), la narcomúsica en América Latina entreteje los relatos sobre el costo social de perseguir el "sueño de la modernidad":

Así, llegamos al siglo XXI y nos encontramos integrados como latinoamericanos vía el narco: sus músicas recorren toda la región, su estilo de vida es el sueńo colectivo del éxito, su moral es la que pega con la sobrevivencia, sus códigos son contados en literatura, cine y telenovelas, su modo de ascender es la ley. $\mathrm{Y}$ en ninguna encuesta nacional aparece como problema, y es porque esta cultura gusta en cuanto nos cuenta cómo somos: sociedades de sobrevivencia, sociedades de la exclusión donde solo se puede avistar el sueño de la modernidad vía lo paralegal [...] el narco

\footnotetext{
${ }^{1}$ Esta distinción entre "lo narco" y "el narco" es retomada por estos autores a partir de Hugo Méndez, quien define "lo narco" como "lo que sobre el narco se imagina. Lo narco es la representación social reconstruida a partir de la emanación de sentido en torno de usos, costumbres, ritos y prácticas de los que comercian con drogas ilegales" (Méndez en Prieto, 2007:s/p).
} 
permite pequeñas felicidades capitalistas; imagina progreso, libertad, igualdad; promete el confort del tiempo libre, las mujeres, el entretenimiento y la figuración social. (Rincón, 2013: 2)

Por otro lado, estas articulaciones entre lo narco y la música poseen un elemento en común que además se encarga en buena medida de hacer efectiva su difusión y aceptación, me refiero a las representaciones de la transgresión: toda referencia a prácticas, actores o situaciones que se encuentran fuera de su respectivo orden normativo. Como elemento de análisis en los narcocorridos, ha sido explorado de diferentes maneras. María Luisa de la Garza (2008) sugiere que el corrido como discurso transgresor es una característica que se remonta a los orígenes del género, en tanto supone dar voz a las "preocupaciones del pueblo" frente a un discurso oficial que las excluye. Pero señala que en los narcocorridos este aspecto no es empleado como un medio para confrontar la tradición autoritaria del Estado, sino para reivindicar la forma de vida y las representaciones del narcotráfico. La autora desacredita la actitud transgresora de los narcocorridos bajo el argumento de que sus demandas no procuran el "bien social", sino intereses personales en los que "al entrar en juego también las fuerzas del mercado, [surge] un equívoco arco de praxis política en el que se entrecruzan imperceptiblemente desafíos y restricciones de verdad (es decir, denuncias y censuras reales) con otras que no lo son" (Garza, 2008: 147).

Así como el narcocorrido se circunscribe a una trama musical que abarca diversas "narcomúsicas" a lo largo del mundo, la fascinación por lo narco, tal como han sugerido diversos autores, se equipara con la fascinación por el bandidismo (bandidos sociales) (véanse, por ejemplo, Edberg, 2004; Cocimano, 2006; Astorga, 1995). En otras palabras, la relación entre música y fascinación por las formas simbólicas del narcotráfico, además de expresarse a través de una variedad vigente de músicas, se remonta a la simpatía popular que han evocado las figuras transgresoras a través de la historia. Gabriel Cocimano (2006) denomina a este referente histórico como la "épica de la violencia” y analiza por medio de la música y literatura cómo la violencia primitiva del bandidismo entraña la violencia marginal de las formas actuales de delincuencia organizada. Asimismo, el autor sugiere que "los códigos de esta violencia pueden ser adoptados y adaptados a cada sociedad, en especial en aquellas que evidencian un debilitamiento institucional y político sobre el que germina la impunidad a gran escala" (Cocimano, 2006: 9).

Por otra parte, Anajilda Mondaca (2012) enfatiza también el elemento de la transgresión y lo considera, junto con la bravura y la valentía, como parte de la mitología de los corridos; por cierto, aspectos que se reafirman "al promover la censura y la crítica sin argumentos sólidos” (2012: 38). Finalmente, Nery Córdova $(2011,2012)$, se dedica ampliamente a explorar la simbología de la transgresión en los narcocorridos desde las implicaciones del narcotráfico en la vida social de Sinaloa. Para este autor la dimensión transgresora de los narcocorridos alude al "submundo" de la ilegalidad que viven algunas entidades federativas del país, pero que se desborda hacia las industrias culturales, ya sea desde la música, el cine o el periodismo. Los medios de comunicación masiva tienen un papel central en la configuración del 
"imaginario de la ilegalidad" ya que, finalmente, el eco de esta "subversión simbólica" se expresa a nivel de la cultura y tiene un efecto legitimador para el tráfico de drogas (Córdova, 2012: 227). Al ahondar en los narcocorridos, Córdova (2011) se refiere a los sujetos de la transgresión como aquellos que, en efecto, se encuentran al margen del orden legal. Sin embargo, el consumo de narcocorridos no se limita a las personas relacionadas con el tráfico de drogas sino que, en contraste, persiste a través del gusto del amplio público, tal como lo han sugerido algunos estudiosos del tema (véanse, por ejemplo, Muehlmann, 2014; Simonett, 2001).

Dado el aporte de estos antecedentes, así como la necesidad de estudiar los sentidos y significados de las personas que encarnan tales productos culturales desde el consumo, considero pertinente abordar el proceso por el cual las representaciones de la transgresión se vuelven ampliamente aceptadas. En concreto, mi interés aquí no es el acto de ilegalidad por sí mismo, sino la manera en que tal acto resulta "disfrutable" para algunos escuchas de narcocorridos.

\section{Narcocorridos y autorreferencia}

En México, "narcocorrido" es una categoría musical que abarca un dilatado conjunto de expresiones que, empezando por la música norteńa y retomando la tradición del corrido, se refieren al tráfico de drogas. Existen diferentes modalidades y estilos que dan lugar a los narcocorridos: desde los que narran hechos históricos, hasta los que hablan del estilo de vida de los narcotraficantes desde dentro del narcomundo. Por otro lado, actualmente la estructura narrativa de los narcocorridos no posee una secuencia fija como la que transcurría entre presentación, desarrollo y despedida. Ni siquiera es necesario hablar directamente de personajes o situaciones relacionadas con el tráfico de drogas para que una composición sea considerada como narcocorrido; basta emplear guiños, códigos o elementos extramusicales para señalar la relación con las representaciones sociales de lo narco.

Una estrategia discursiva de los narcocorridos a través de la historia ha sido la de "autorreferencialidad". Me refiero a la cualidad de una narración para interpelar al escucha a través de las condiciones de existencia que recrea y en las que éste se siente sujeto de la narración. Considero que a pesar de que la autorreferencialidad ha sido un recurso empleado en los narcocorridos desde sus comienzos, se explota actualmente aún más por sus compositores; de hecho, gran parte de los narcocorridos más populares en la actualidad están narrados en primera persona. Muestra de ello son algunos de los narcocorridos más populares en los últimos años según visitas de youtube, como lo son "Dámaso" (2012) interpretado por Gerardo Ortiz, "El Karma" (2014) con Ariel Camacho y más recientemente, "Del negociante" (2016) de Los Plebes del Rancho. ${ }^{2}$ Sobre la autorreferencia, el filósofo Luis Álvarez Falcón indica que,

\footnotetext{
${ }^{2}$ Por lo regular estas listas de éxitos se calculan con base en el número de reproducciones al aire en radiodifusoras y el número de descargas legales; por ejemplo, Charts club México o Billboard en su categoría de Regional Mexicana en Estados Unidos.
} 
En el ámbito de la estética, la "autorreferencia" aparece como un esquema de re-aplicación, como una "autoscopia" inmanente, como un reflejo inclusivo del sujeto en la "obra", o como un esquema recursivo de la propia "obra", tanto desde el nivel de sus relaciones formales (sintaxis), como desde el nivel semántico (términos) y del nivel pragmático (operaciones). (Falcón, 2010: 31)

Por otro lado, Lucila Lobato (2009) aclara que la enunciación y la narración en primera persona del singular permiten que el intérprete genere un vínculo más cercano entre la voz lírico-narrativa y su auditorio; se intensifica así el drama que dicha puesta en escena entraña (Lobato, 2009: 132). Asimismo, Lobato se refiere al corrido desde Raúl Dorra, como un conjunto de imágenes que hacen proliferar una psicología individual donde el temperamento se impone a la convención que, como resultado, genera una aproximación afectiva ligada por la narración en primera persona (132). Pero antes de profundizar en los aspectos que detonan el disfrute de estas expresiones musicales, es necesario dar cuenta del tipo de contextos donde son ampliamente aceptadas, así como de algunos aspectos metodológicos que implica su análisis.

\section{Los narcocorridos en la frontera: el caso de la ciudad de Mexicali}

El camino que atraviesa un narcocorrido a lo largo del ciclo de producción culmina en un lugar predilecto: el del escucha. Pero éste, como aclara César Burgos "no es una masa pasiva que consume música como churros, sino una comunidad activa a la que la música no impone una ideología, aunque puede absorber los valores e intereses de sus oyentes" (2012: 61-62). En ese sentido, la letra de los narcocorridos sólo refleja una dimensión parcial de su fuerza social. Los narcocorridos implican, también, espacios de socialización, motivaciones en los músicos e identidades musicales de los escuchas.

Mexicali, ciudad capital de la entidad de Baja California, se ubica en el extremo noroeste de México en la frontera con Estados Unidos. Al igual que su demografía, la ciudad ha sido receptora de músicas migrantes, especialmente la sinaloense. ${ }^{3}$ Para la etnomusicología, la música es proveedora de un marco sonoro a través del cual se genera una experiencia sensorial, estética e intelectual (Carvalho, 1995). Los pobladores de esta ciudad han empleado ese marco de una manera particular. En la cotidianidad mexicalense, los narcocorridos desfilan desde una gran cantidad de situaciones, soportes y formatos: en los supermercados, en los carros durante la parada del semáforo, en una rocola durante fiestas familiares o reuniones entre amigos, en un restaurante de mariscos "estilo sinaloense", frente al monitor de la computadora o del teléfono a través de redes sociales, desde el patio de la casa de los vecinos, en el transporte público pese a la censura o desde los altavoces del teléfono móvil de un transeúnte (observación propia, 12 de julio de 2015). ${ }^{4}$ La música norteńa y,

\footnotetext{
${ }^{3}$ La presencia sinaloense en la ciudad no es menor. Baja California es un destino notable de la migración de sinaloenses, así que la influencia cultural no se limita a la música y abarca otros aspectos, como la gastronomía.

${ }^{4}$ Máquina de música que funciona con monedas.
} 
en especial los narcocorridos, pueblan buena parte del paisaje sonoro de la ciudad, tanto de noche como de día, en espacios públicos y privados.

Mexicali colinda con Calexico, California, que es una ciudad de mucha menor población, pero junto con la que constituye uno de los cruces fronterizos más transitados de la frontera entre México y Estados Unidos. Como señala González, la producción del corrido de narcotráfico ha evolucionado estrechamente ligado a la lógica económica de la región fronteriza de estos dos países (2016: 95). Es muy común ver placas vehiculares del estado de California en la ciudad, pero es especialmente común que en los antros, bares o cantinas donde se escuchan narcocorridos se vean aún más las placas californianas (observación propia, 12 de julio de 2015). Una de las razones de ello es que en Calexico no hay tantas opciones para la vida nocturna, además de que resulta más cómodo para los asistentes recrearse del lado mexicano por diversos motivos como los precios, los horarios y la variedad de lugares. Sin embargo, del lado estadounidense hay lugares donde es posible escuchar música norteña, como es el caso del restaurante La Resaca (que en su momento, fue una franquicia presente en ambas ciudades fronterizas).

A pesar de que Baja California no tiene la historia musical que tienen otras entidades norteńas como Sinaloa, Nuevo León, Chihuahua o Tamaulipas, ha sido una "plaza musical" importante para la recepción debido a sus condiciones geopolíticas y a su composición poblacional. La ruta migratoria de comunidades sinaloenses a municipios como Tijuana o Mexicali lleva varias décadas de consolidarse (Sánchez, 2012). ${ }^{5}$ La música sinaloense no sólo ha sido adoptada por muchos de sus pobladores, sino que encuentra aquí un espacio de difusión idóneo para los narcocorridos, ya que como comenta Pepe Saldívar, productor musical radicado en Mexicali:

Vas a Culiacán y de hecho en todo Sinaloa hay corridos en los carros pero no están en la radio en los antros no suenan los corridos. Por lo mismo a lo mejor de las mafias que no puedes tocar cualquier corrido [...] Si tú te vas a Culiacán no hay espacio para esta música, de regional. Creo que en Culiacán sólo hay uno o dos lugares con esta música máximo. O sea es irónico que los músicos sean de allá y no tengan donde tocarla. (Pepe Saldívar, productor musical, comunicación personal, 1 de julio de 2015)

De esta variedad de formas en que se presentan la música norteña y los narcocorridos, es necesario delimitar la observación a un lugar específico. En aras a comprender el disfrute y la puesta en escena de estas expresiones, considero que el concepto de "espacios sociomusicales" es clave para avanzar en este cometido. Juan Ramírez Paredes define los espacios sociomusicales como "sitios en donde existe una sociabilidad a partir de la propia música" (Ramírez, 2012: 182n). Se trata de lugares en donde el sentido de la acción social se encuentra mediado por la música, y que pueden tomar forma de una cantina, bar o centro de espectáculos. A diferencia de otras situaciones en que la

5 Tan sólo en 2005, de las 101.088 personas que emigraron de Sinaloa, un 28\% se instalaron en Baja California, figurando como el principal destino de los migrantes sinaloenses, por encima de Sonora, Jalisco y Baja California Sur (INEGI, 2005). 
cotidianidad es musicalizada, los espacios sociomusicales guardan un estrecho vínculo entre música y motivaciones. Por lo tanto, son espacios donde se escenifica la compleja red de actores relacionados con la producción y reproducción de los narcocorridos.

El reto aquí es analizar la música desde una aproximación etnográfica. La etnografía es un método de comprensión que a través de una descripción sistematizada permite conocer a profundidad un aspecto de la cultura. Esta "descripción sistematizada" y la particularidad del conocimiento que produce se definen mínimamente por dos técnicas de investigación: la observación participante y la entrevista etnográfica. La primera tiene como objetivo describir las actividades humanas y las secuencias en que se presentan, el comportamiento físico y sus modos de interactuar, desde la inmersión a las dinámicas de los informantes (Krüger, 2008: 58). La segunda busca explorar los significados que tales prácticas tienen para los informantes mediante una conversación pautada que se lleva a cabo en el ambiente propio del objeto de investigación.

Antes de dar cuenta del papel de la transgresión y la autorreferencia desde los espacios sociomusicales de los narcocorridos, cabe precisar cómo fueron empeladas estas herramientas metodológicas. Además de las dos técnicas atrás mencionadas, se recurrió a pláticas informales de manera aleatoria con la intención de entablar cercanía con posibles entrevistados. Una vez establecida esta aproximación a lo largo de diferentes visitas a espacios sociomusicales entre 2015 y 2016, se tomaron notas y registro audiovisual para analizar las interacciones y formas de respuesta a la música. Posteriormente, se aplicaron nueve entrevistas tanto a hombres como mujeres que afirmaron asistir con frecuencia a dichos lugares. Finalmente, estos datos se contrastaron con el análisis de contenido de los narcocorridos con base en la relación entre sonido, letra y dotación expresiva de los escuchas, particularmente desde dos narcocorridos cada uno en eventos diferentes que, además de haber sido reconocidos por los informantes como uno de sus favoritos, generaron mayor respuesta entre los asistentes: estos fueron "Toro encartado" y "Al estilo italiano".

Una precisión conceptual no menos importante es la que conllevó la elección de la categoría "disfrute" en contraste con otras categorías circundantes. En primer lugar, cabe señalar que el consumo, en tanto la relación de un individuo con los bienes y servicios, incluye a la categoría de disfrute. En específico, el concepto de "disfrute mediático" ha sido analizado desde un área de estudio en la que convergen la psicología positiva y el análisis de la comunicación de masas (Bryant y Vorderer, 2006; Sherry, 2004). Así, el concepto de disfrute "se equipara con la experiencia de estados emocionales placenteros por el consumo de un producto de ficción determinado [independientemente de la valencia de ese estado emocional]" (Igartua y Muñiz, 2008: 26). Otras categorías de estudio que tocan tangencialmente a la de "disfrute" serían "gusto" y "recepción"; sin embargo, la primera tiene una fuerte connotación bourdiana apoyada en el concepto de habitus (Bourdieu, 2002), y la segunda una predilección en los estudios de comunicación de masas orientados a analizar públicos y audiencias. Mi intención es emplear el 
concepto de disfrute como una vía para comprender la apropiación subjetiva de la música desde diversos aspectos, como las imágenes sonoras de los narcocorridos, las expresiones corporales de los escuchas y el punto de vista de los mismos.

\section{Los escuchas desde los espacios sociomusicales: una aproximación etnográfica al disfrute de narcocorridos}

Después de sopesar por largo rato un "plan de ataque" para entrevistar a personas que escucharan narcocorridos y asistieran a presentaciones en vivo con regularidad, decidí recorrer algunas calles de la zona comercial de la ciudad para estimar cuál lugar tenía las mejores condiciones de estudio. Los criterios fueron: un lugar concurrido, donde la energía emocional sería más evidente, y que tuviera un espacio a la intemperie para que las entrevistas no fueran inundadas por el volumen de la música. Decidí caminar por uno de los corredores de música norteña (calzada Aviación). Probé suerte en el centro nocturno El Relajo, pero como ahí se alterna música norteña, reguetón y música electrónica, muchas de las personas que abordé me dijeron que el tipo de música que más les atraía del lugar era el reguetón. Con sospechas, crucé la calle y decidí intentarlo de nuevo en La Frontera, una cantina especializada en música norteńa y en donde se toca en vivo seis días a la semana. Me instalé en la entrada del lugar y obtuve mejores resultados. Sin embargo, me llamó la atención que la mayoría de los asistentes que abordé me dijeran que no les gustaban tanto los narcocorridos. Me extrañó porque tiempo atrás había entrevistado al encargado del lugar y me contó que "aunque suenan baladas y cumbias norteńas, los clientes siempre se piden corridos todo el día” (El Bebé, encargado de cantina norteńa, comunicación personal, 9 de febrero de 2016) y, de hecho, pude constarlo en más de una visita.

A reserva de que la gente negara el gusto por los narcocorridos para evitar ser entrevistada o que se tratara del tipo de asistentes atraídos por las cumbias o baladas norteñas, o que simplemente lo hayan negado por temor a ser juzgados, me llamó la atención que la gran mayoría me dijeran que lo que les gustaba del lugar independientemente del estilo musical era el "ambiente". Esta categoría emic me permitió comprender un aspecto definitivo de los espacios sociomusicales: la importancia de la dimensión emocional en tanto actividad ritual. En términos de Randall Collins (2009) el "ambiente" sería la energía emocional que concentra un ritual de interacción; en términos de Gluckman (1978), la capacidad de generar sentimientos de solidaridad. En suma, el "ambiente" es un aspecto crucial para contestar la pregunta sobre qué papel tienen los narcocorridos en la socialización de los escuchas.

Los mismos asistentes que habían mostrado reserva sobre su afinidad a los narcocorridos desplegaban una serie de actitudes diferentes durante el transcurso del evento. Si bien no cantaban las canciones ni parecían del todo interesados en los músicos, respondían a los momentos en que la canción hablaba de cuestiones relacionadas con las armas, muerte o autoafirmación a través de los logros económicos y el trabajo. Sin embargo, cada grupo de asistentes interactuaban de manera distinta entre sí y respecto a la música; 
algunos cantaban gran parte del repertorio, otros bailaban en pareja aun cuando sonaban narcocorridos. La Frontera tiene un aforo aproximado para 150 personas. Como cantina, tiene una barra que abarca el ala poniente del lugar, misma orientación donde se encontraban los músicos de banda sinaloense, estilo que forma parte de la música norteña. La distribución del espacio, la colocación de las mesas y, en suma, la proxemia del lugar implicaban la convivencia cercana entre asistentes y músicos, ya que estos no usaban una plataforma o escenario, sino que se distribuyen entre el público y los trabajadores del lugar.

Uno de los narcocorridos interpretados ahí fue el de "Toro encartado" (originalmente grabado por el cantante Ariel Camacho). El sonido de las flautas se reviste por el ronquido de una tuba, grave y entrecortado, que se impone al fondo de canción. Después entra el acompañamiento de la tarola que imprime el aspecto bélico al ambiente, similar al de las marchas militares (Diario de campo, 1 de abril de 2016). La voz comienza:

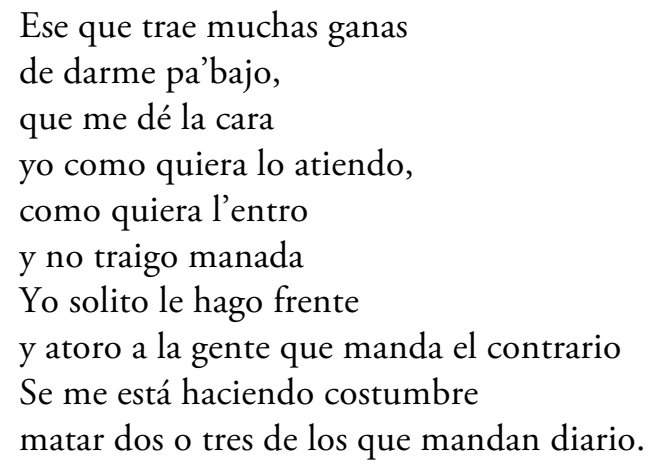

Tras esta escena entrevisté a Roberto, joven universitario quien platicó que trabajaba en el gobierno de la entidad, y que además fue uno de los pocos en aceptar abiertamente que le gustaban los narcocorridos: "Pues a mí me gusta, a veces el significado que tienen. Pero yo lo relaciono con mi vida, para lo bueno [...], para lo que hago en mi trabajo y cómo lo hago" (Roberto, estudiante, comunicación personal, 1 de abril de 2016). Continuó aclarándome que él nota que los antros donde se tocan narcocorridos, la gente asiste a bailar o a "empaparse del ambiente": "los corridos viejitos como que sonaban todos igual y pues como que la gente viene más que escucharlos, a bailarlos" (Roberto, estudiante, comunicación personal, 1 de abril de 2016).

Simon Frith (1998), en su libro Performing Rites, propone que "al escuchar música popular no sólo estamos escuchando un performance, sino que en el fondo, el 'escuchar' es en sí mismo un performance” (1996: 203-204; traducción propia). La puesta en escena de los escuchas implica también una estética, un conjunto de reglas para percibir algo que se desvía de la norma, diríamos, una estética de la transgresión, empezando por el hecho de que tocar narcocorridos tiene ya una carga de ilegalidad, puesto que en Baja California han habido distintas iniciativas para censurarlos en el transporte público y otros espacios. Pero no se trata del rompimiento de cualquier norma, sino de aquellas que tienen que ver con la manera de generar capital tanto económico como simbólico. El sonido se vuelve resistencia estética, porque aun cuando ha 
pasado por el trabajo de ecualización de un ingeniero, pugna por salir de los parámetros de la alta cultura o de "lo culto": una voz nasal que canta con palabras a medio pronunciar, un rasgueo de cuerdas con altibajos o un instrumento de viento cuyos graves colman la escucha y hace retumbar las ventanas.

La música norteńa y los narcocorridos representan gran parte de la oferta de música en vivo de la ciudad y esto se refleja en dos aspectos: primero, en el número de lugares destinados a su reproducción, pues la mayoría tiene música en vivo casi todos los días de la semana, motivo por el cual cuentan con grupos de casa, ya sea, grupos norteńos o banda estilo sinaloense. Y, segundo, en el aforo de los mismos, ya que de los 17 lugares visitados, la mitad tiene una capacidad mayor a 500 personas, cantidad de personas, que según los entrevistados y observación propia, se aproxima en número de asistentes cada fin de semana.

Seguí en el bar La Frontera, donde platiqué con varios asistentes en torno al "ambiente" en los lugares donde se toca narcocorridos y sus opiniones como escuchas. De los entrevistados ninguno afirmó que el principal atractivo de estos lugares fuera escuchar corridos. En cambio, varios de ellos se refirieron al ambiente, la música o al "lugar" como aquello que les motivaba a asistir a estos espacios. Sin embargo, durante las tres horas que estuve en el lugar, se escucharon narcocorridos continuamente: "La vida ruina", "Dámaso", "Tomen nota”, entre otros.

El disfrute es algo más que el simple hecho de acudir a escuchar o presenciar la música. Para el escucha, el espacio es un factor que confiere sentidos distintos a la música: no es lo mismo escucharla desde los audífonos que desde un centro nocturno. Este "disfrute" fue verbalizado por algunos asistentes como una atracción hacia el "ritmo" o hacia cómo suenan. Marisol, maestra de primaria, también me platicó sobre su gusto hacia los narcocorridos; dijo que lo atrayente de estas expresiones son "varias cosas, o sea depende, como que primero lo que te gusta es el ritmo y ya después te fijas más en la letra. Y muchas veces ya que te das cuenta de la letra, ya se te pegó o se te grabó aunque realmente no trae buen contenido (Marisol, maestra, comunicación personal, viernes 1 de abril de 2016).

El "significante narco" implica una forma de hacer para otros y para sí mismo. Así, lo que se describió desde Frith como "performance del escucha” tiene que ver con la "presentación de la persona" en Erving Goffman (1981), es decir, con la proyección del "yo" que ejecuta un individuo frente a un grupo de observadores. El auge de los narcocorridos y otras formas simbólicas del narco no sólo deber ser entendido por la situación actual del país, sino por la capacidad de articular un marco sonoro con una dotación expresiva y una forma de percibir el mundo.

Hablar de la actitud performativa de los escuchas de narcocorridos implica también hablar de quienes lo ponen en acto desde la indumentaria, las expresiones y los gestos. Consumir un producto cultural no es igual a ser el receptor de una idea sin más; en vez de ello, supone un trabajo de representación para sí y para otros. El Korral es un antro ubicado en la zona hotelera, en la intersección con la avenida Justo Sierra, calle principal del 
conglomerado urbano y de referencia turística. A media manzana se encuentra el fraccionamiento Los Pinos, uno de los de mayor plusvalía en la ciudad. Sobre esa misma cuadra se encuentran lugares de rock, pop y música electrónica. El Korral, se anuncia como un "rodeo de medianoche con norteño y banda"; cada viernes tiene música en vivo con algún grupo local como Doble Sello o Contraste Sierreńo. También alberga eventos especiales como la presentación de Jesús Ojeda el día sábado 14 de marzo de 2015 y al que me referiré a continuación.

Los asistentes al evento aparentan perfiles diversos. En primera instancia, se observan diferencias en aspectos materiales y estéticos: los automóviles que ingresan al estacionamiento (carros del año y modelos de más de veinte años, carros sedán y camionetas) y la vestimenta que varía entre los mocasines, las botas vaqueras, gorras estilo New Era (marca oficial de los equipos de béisbol de la región) y en menor medida, sombrero vaquero. Las mujeres optan por vestidos de lycra ceñidos, faldas cortas de colores fuertes y otras con mezclilla y zapatillas de tacón alto, acompañadas de bisutería y relojes frecuentemente llamativos. Pero el perfil de los asistentes es diverso. Esto se aprecia también en las edades (desde jóvenes universitarios hasta adultos de 3540 años) o en las formas de consumo (whiskey Buchanan's, tragos preparados, alguna botella de ron y regularmente cerveza).

Jesús Ojeda es un cantante reconocido de narcocorridos, uno de los primeros que tocó durante el evento fue el de "Al estilo italiano". El corrido hace referencia a un personaje del narcotráfico que viste y se comporta como "italiano", idea que por cierto, constituye representaciones sociales recurrentes en los narcocorridos actualmente. Numerosos ejemplos dan cuenta de ello, como el corrido de "La última sombra" interpretado por Gerardo Ortiz o el de "La mafia se sienta en la mesa" de El Komander, que explícitamente refieren a lo "siciliano" o la "mafia italiana" como modelos a seguir. Tales alusiones se expresan también en las marcas comerciales de ropa y accesorios como Gucci o Salvatore Ferragamo que aparecen en varios videos musicales, en los que incluso dichas marcas se mencionan explícitamente.

Pero para rastrear la forma en que el escucha se autorrepresenta a través de la música, es necesario sumar otros aspectos, tales como los gestos y las expresiones. Durante el corrido (Al estilo italiano), el público silba, canta y aplaude cuando comienza el requinto del corrido, sonido que evoca los riffs de la música country. Jesús grita “¿iSe la saben!?”, y cede al público la letra de la canción. Interviene sólo para marcar los inicios de cada estrofa: "El Güero Bastidas me brinda su apoyo...”. El público continúa el verso. En una de las transiciones entre una estrofa y otra, un joven levanta su mano derecha con el índice extendido, sacudiendo el brazo de un lado a otro, al tiempo que él junto con los demás asistentes terminan la estrofa: “...También es mi amigo” (diario de campo, sábado 14 de marzo de 2015). Esta escena refleja un aspecto importante del lenguaje no verbal de los asistentes. Me refiero a la mano extendida con el índice hacia arriba, el cual es una reacción común en los asistentes en este y otros eventos musicales. En general, la mímica que comprende este movimiento es la misma que se emplea al momento de pedir la palabra o que se ejecuta para responder a una lista de asistencia. Se trata de una 
expresión aprendida desde el espacio escolar para exhibir la presencia propia ante un grupo; en suma, un aspecto más que indica "referencia a uno mismo".

\section{Conclusión. ¿Hacer como narco o hacer lo que los narcos hacen?}

En ambos espacios sociomusicales, los asistentes realizaron las mismas actividades que se llevan a cabo en otros eventos musicales: beben cerveza, brindan, fuman, platican, se carcajean, gritan, bailan, tararean la música, cantan, contemplan su derredor, se toman fotos. Menos común es el conjunto de discursos que son permitidos bajo lo que Gluckman (1978) llama "enmascaramiento" ritual, que es una forma de anonimato en que se experimenta cierta "libertad" para hacer o decir cosas que comúnmente no son bien vistas por un grupo; por ejemplo, para socializar las representaciones sociales del narcotráfico. Hablar de disparos, de muerte, de los sentimientos de revancha, incluso de exclusión social y económica, adquieren estatus de discurso permitido. Mientras que dichas acciones estarían expuestas a la sanción social en muchos otros espacios de la cotidianidad. La "sensación transgresora" deriva del estado liminal del que habla Turner (2008): un momento en el que es posible hacer y decir cosas sin que la persona sea juzgada por ello.

Un principio subyace a la presente descripción: a no ser de que se trate de un estudioso de la música o un curioso explorador sonoro, en nuestra vida cotidiana, optamos por la música que nos provoca algo, ya sea una emoción, sentimiento o estado de ánimo; de otra manera es difícil disfrutarla. Y aunque la música puede ser escuchada por diversos motivos y fines, considero al "disfrute" (de los escuchas) una etapa clave para entender el ciclo de los narcocorridos. Vale aclarar que este efecto de disfrute, como señalaría Pierre Bourdieu (2002), es una forma en que se expresa el habitus. Desde aquí, el gusto es una disposición inconsciente que se produce y reproduce desde dos aspectos principales: la trayectoria de vida del individuo y el conjunto de capitales que se entrecruzan en su posición dentro del espacio social. ${ }^{6}$

Una interpretación del disfrute de la música popular responde al hecho de sentirse interpelado por las condiciones de existencia que retrata la canción. Tal y como lo verbalizan algunos músicos, "la plebada se siente el del corrido" (Jesús, vocalista de Xperiencia sierreña, comunicación personal, 24 de enero de 2015). ${ }^{7}$ Así pues, aunque los narcocorridos descritos combinan formas gramaticales, la autorreferencialidad es más evidente cuando se emplea la primera persona.

En suma, escuchar narcocorridos no es igual a compartir el mundo de vida de los narcotraficantes. Por "sensación de transgresión" me he referido a la propiedad de una forma simbólica para hacer sentir al receptor que transgrede; es en buena medida la recreación mental del rompimiento de las normas. En la música, esto implica analizar el disfrute en el tránsito entre la sensación

\footnotetext{
${ }^{6}$ Para Bourdieu (2002), ambos aspectos, uno diacrónico (procedencia, familia, etc.) y otro sincrónico (situación presente del individuo), son internalizados y expresados a través del habitus; por ejemplo, a través del acento en el habla.

7 "Plebada" es utilizado en Sinaloa y otros estados para referirse a los jóvenes o niños en general, aunque aquí hace se refiere específicamente a los "jóvenes asistentes".
} 
conferida por las imágenes literarias de la letra, el aspecto sonoro que la canción sugiere y el espacio de socialización. Respecto a las primeras dos, la relación entre imágenes literarias y sonoras de los narcocorridos puede ser reconstruido al conectar la "autorreferencia" con la sensación transgresora que evocan. Se trata de un binomio que expresa buena parte de la fuerza social de los narcocorridos.

La industria cultural de lo "narco" es cada vez más rentable, acapara mayor audiencia y abarca públicos más diversos. Mientras que la "sensación transgresora" nos sitúa en la perspectiva de la experiencia y de los sentidos, podríamos hablar también de un "performance de la transgresión" en el escucha: una puesta en escena en el hacer cotidiano. Para los escuchas de narcocorridos, puede tratarse de una forma de motivación a la vez que un acto público. La puesta en escena de los narcocorridos en la cotidianidad de Mexicali, recubre las prácticas con un halo de trasgresión; se encarga de imprimir a las prácticas una apariencia de bravura y atrevimiento, independientemente del oficio o profesión de sus actores: hacer como narco, no hacer lo que hacen los narcos.

En concreto, los valores que emanan de las representaciones del tráfico de drogas en los narcocorridos empatan con muchas de las consignas laborales en el presente: ser proactivo, resiliente y leal, pero sin dejar de ser osado para confrontar las normas cuando éstas sean obstáculo para lograr un progreso económico. La sensación de transgresión o "subversión simbólica", como la llama Córdova (2012), opera en los agentes desde distintos campos, clases y formas simbólicas. Diferentes géneros musicales en contextos históricos específicos han encarnado formas de transgresión que los ha llevado incluso a ser censurados.

El desarrollo actual de los estilos musicales que dan vida a los narcocorridos, da cuenta, según el concepto de Hall explicado al inicio, de cómo ciertos elementos se articulan continuamente para hacer inteligible una situación histórica (Hall, 2010: 49). El estado actual de los narcocorridos refleja, por un lado, los flujos migratorios de las comunidades transnacionales y la violencia relacionada con los avatares del (y contra) el narco. Pero, por otro lado, refleja el papel de la música como eje de interpretación de la realidad social. La música traduce una serie de acontecimientos que transcurren en el horizonte cotidiano en datos sensibles: es una urdimbre que entrelaza el marco sonoro de un grupo social con las emociones de sus actores, confiere sentido a las prácticas y en ese sentido contribuye a su integridad social.

\section{BIBLIOGRAFÍA}

Álvarez FALCÓN, Luis (2010), “La 'autorreferencialidad' de la experiencia estética”, Fedro, n. ${ }^{\circ}$ 9, pp. 30-42.

Astorga, Luis (1995) Mitología del "narcotraficante" en México. México, UNAM-Plaza y Valdés.

Bourdieu, Pierre (2002) La distinción. Criterio y bases sociales del gusto. Buenos Aires, Taurus. 
BRYANT, Jennings; Vorderer, Peter (editores) (2006), Psychology of entertainment. Nueva Jersey, Lawrence Erlbaum.

Burgos DÁVILA, César (2012), "Mediación musical: aproximación etnográfica al narcocorrido". Tesis de doctorado, Barcelona, Universidad Autónoma de Barcelona.

CARvalHo, José Jorge de (1995), Hacia una etnografía de la sensibilidad musical contemporánea. Brasília, Universida de Brasília.

Cocimano, Gabriel (2006), "De la épica del bandidismo a la tragedia del pandillismo: clase, poder y violencia en América Latina”, Culturas populares, n. ${ }^{\circ}$ 3, pp. 1-14.

CÓRDOVA, Nery (2011), La narcocultura: simbología de la transgresión, el poder y la muerte. Sinaloa y la leyenda negra. Culiacán, Universidad Autónoma de Sinaloa.

(2012) “La narcocultura: poder, realidad, iconografía y mito", Cultura y representaciones sociales, vol. 6 , n. ${ }^{\circ}$ 12, pp. 209-237.

CRAGNOlini, Alejandra (2006), "Articulaciones entre violencia social, significante sonoro y subjetividad: la cumbia villera en Buenos Aires", Trans, n. ${ }^{\circ} \quad 10 . \quad$ Consultado en <http://www.sibetrans.com/trans/publicacion/5/trans-10-2006> (14 de abril de 2016).

EDberG, Mark (2004), El Narcotraficante: Narcocorridos and the Construction of a Cultural Persona on the U.S.-Mexican Border. Austin, University of Texas Press.

IgARTUA, Juan José; MuÑIZ, Carlos (2008), "Identificación con los personajes y disfrute ante largometrajes de ficción. Una investigación empírica”, Comunicación y Sociedad, vol. 21, n. ${ }^{\circ}$ 1, pp. 25-52.

FriTh, Simon (1998), Performing Rites. Cambridge, Universidad de Harvard.

GarZA, María Luisa de la (2008), Pero me gusta lo bueno. Una lectura ética e los corridos que hablan de narcotráfico y de los narcotraficantes. México, Universidad de Ciencias y Artes de Chiapas.

GlucKman, Max (1978), Politica, derecho y ritual en la sociedad tribal. Madrid, Akal.

GOFFMAN, Erving (1981), La presentación de la persona en la vida cotidiana. Buenos Aires, Amorrortu.

GONZÁLEZ, Igael (2016), "Entre la censura y los negocios: notas sobre la industria del corrido de narcotráfico y de la nueva música regional mexicana", Methaodos, vol. 4, n. ${ }^{\circ}$, pp. 87-99.

Hall, Stuart (2010), "Sobre postmodernismo y articulación", en Restrepo, Eduardo (ed.), Sin garantías. Trayectorias y problemáticas en estudios culturales, Popayán, Envión, pp. 75-93.

KRÜGER, Simone (2008), Ethnography in the performing arts. Liverpool, John Moores University.

LOBATO OSORIO, Lucila (2009), "Narcocorridos en primera persona: la caracterización del personaje", en Zavala Gómez del Campo, Mercedes (ed.), Formas narrativas de la literatura de tradición oral de México: romance, corrido, décima, leyenda y cuento. San Luis Potosí, El Colegio de San Luis, pp. 131-164. 
Mainold, Günther; SAUTER, Rosa María (2012), "Capos, reinas y santos-la narcocultura en México", iMex, año 2, n. o 3, pp. 64-96.

MoncADA, Anajilda (2012), Narcocorridos, ciudad y vida cotidiana: espacios de expresión de la narcocultura en Culiacán, Sinaloa. Tesis de doctorado, Tlaquepaque, Instituto Tecnológico de Estudios Superiores de Occidente.

Muehlmann, Shaylih (2014), When I Wear My Alligator Boots: Narco-Culture in the U.S.-Mexico Borderlands. Berkeley, Universidad de California.

RAMíREZ PAREDES, Juan Rogelio (2012), "Huellas musicales de la violencia: el 'movimiento alterado' en México", Sociológica, vol. 27, n. ${ }^{\circ}$ 77, pp. 181-233.

RAVVEDUTO, Marcello (2012), "Musiche, neomelodici e criminali", en Ciconte, Enzo; Forgione, Francesco; Sales, Isaia (eds.), Atlante delle mafie. Storia, economia, società, cultura. Catanzaro, Rubbettino, pp. 301-324.

RinCÓN, Omar (2009), "Narco.estética y narco.cultura en Narco.lombia", Nueva Sociedad, n. ${ }^{\circ}$ 222, pp. 147-163.

(2013), "Todos llevamos un narco adentro - un ensayo sobre la narco/cultura/telenovela como modo de entrada a la modernidad", Matrizes, vol. 7, n. $^{\circ} 2$, pp. 1-33.

SHERrY, John L. (2004), "Flow and media enjoyment", Communication Theory, vol. 14, n. ${ }^{\circ}$, pp. 328-347.

SimOneTt, Helena (2001), "Narcocorridos: An Emerging Micromusic of Nuevo L. A.”, Ethnomusicology, vol. 45, n. ${ }^{\circ}$ 2, pp. 315-337.

SNEED, Paul (2007), "Representations of the Power of Criminal Factions in Rio's Proibidão Funk”, Latin American Music Review, vol. 28, n. ${ }^{\circ}$ 2, pp. 220-241.

TURNER, Víctor (2008), "Dramas sociales y metáforas rituales”, en Antropología del ritual. Ingrid Geist (comp.). México, INAH.

ValenZuela, José Manuel (2003), Jefe de jefes: Corridos y narcocultura en México. México, Plaza y Janés.

(2012), "Narcocultura, violencia y ciencias socioantropológicas", Desacatos, n. ${ }^{\circ} 38$, pp. 95-102.

WaLD, Elijah (2001), Narcocorrido. A Journey Into The Music Of Drugs, Guns, And Guerrillas. Nueva York, Rayo. 